\title{
Derleme
}

Mersin Univ Saglık Bilim Derg 2019;12(1):136-142

doi: 10.26559/mersinsbd.474682

\section{Talidomit faciasının farmakovijilans etkinliklerinin gelişimi üzerine etkisi}

\author{
Cüneyt Kemal Buharalığlu1, Gökçe Yıldırım Buharalığlu²
}

${ }^{1}$ Doç. Dr., İzmir Katip Çelebi Üniversitesi, Eczacılık Fakültesi, Farmakoloji Anabilim Dalı

2 Dr. Araştırma Görevlisi, Ege Üniversitesi, Eczacılık Fakültesi, Klinik Eczacılık Anabilim Dalı

$\mathrm{Bu}$ derlemede, tarihsel bir yaklaşımla, talidomit kullanan gebelerin fokomelili bebeklerinin doğumu sonrasında yaşananlar değerlendirilerek, bu facianın sistematik farmakovijilans etkinliklerinin gelişimine etkisi araştırılmıştır. Bu amaçla, ilgili anahtar kelimeleri içeren PubMed taraması yapılarak çalışmamızın amacı ile uyumlu bilimsel makaleler ve tarihsel bilgileri içeren derlemeler çalıșmamıza dahil edilmiştir. Bulgularımız teratojenisite, ilaç güvenliliği ile ilgili etik ve yasal düzenlemeler, ilaçların geliştirilmesi ve pazarlama sonrası gözetimi gibi önemli farmakovijilans etkinliklerinin gelişiminde talidomit faciasının nasıl bir itici güç olduğunu vurgulamıştır. Talidomidin kütanöz lepranın ve multipl myelomanın tedavisinde kullanılmak üzere yakın geçmişte ilaç piyasasına geri dönüşü ilaç güvenliliğine bakış açımızı değiștirmiş ve risk yönetimini ön plana çıkartmıştır. Sonuç olarak; talidomit faciasının ardından yaşananlara günümüzün gözüyle bakmak, farmakovijilans etkinliklerini daha iyi anlamamızı sağlamakla birlikte önümüzdeki yıllarda farmakovijilansı bekleyen zorlukları belirleyip çözmemize yardımcı olma potansiyelini de taşımaktadır.

Anahtar Sözcükler: Talidomit, farmakovijilans, ilaç güvenliliği

\section{Effects of thalidomide disaster on the development of pharmacovigilance activities}

\begin{abstract}
In this review, the effects of thalidomide babies on the development of systematic pharmacovigilance activities were searched with historical perspective. For this purpose, after PubMed search with relevant keywords, scientific studies that serve our purpose were included and historical information was obtained from the reviews. Our results underlied the fact that thalidomide disaster was the main driving force for the development of important pharmacovigilance activities such as teratogenicity, ethical and legal regulations on drug safety, drug development and post-marketing drug surveillance. Currently, the return of thalidomide in the treatment of cutaneous leprosy and multiple myeloma has changed our view on drug safety and highlighted the importance of risk management. As a result, looking at the thalidomide disaster from today's perspective will help us not only to better understand pharmacovigilance activities but also to identify and solve the challenges that are waiting in the coming years.
\end{abstract}

Key words: Thalidomide, pharmacovigilance, drug safety

Yazının geliş tarihi:25.10.2018 Yazının kabul tarihi:24.12.2018

Sorumlu Yazar: Cüneyt Kemal Buharalığlu, Balatçık Mahallesi Havaalanı Şosesi No:33/2 Balatçık 35620 Çiğli İzmir, Türkiye, Tlf: 02323293535/6107, e-posta: bkemalc@gmail.com 


\section{Giriş}

Günümüzde neredeyse her birkaç yllda ters (advers; ilaca ait beklenmeyen, istenmeyen ve zarar verici etkiler) etkilerinden dolayı bazı ilaçlar toplum gündemine oturmakta ve sağlık çalışanları kadar bu ilacı kullananlar ve kullananların ailelerinde endişelere yol açmaktadır. Kelime anlamı ilaçların (pharmakon) zararlı etkilerine karşı tetikte olmak (vigilance) olan farmakovijilans; Dünya Sağlık Örgütü (DSÖ) tarafından ilaçların ters etkileri ve ilgili diğer problemlerin tespiti, değerlendirilmesi, anlaşılması ve önlenmesi ile ilgili etkinlikler ve bu konuları kapsayan bilim dalı olarak tanımlanmıştır. ${ }^{1}$

Farmakovijilans etkinlikleri içerisinde; ilaçların güvenlilik verilerinin toplanması ve yönetimi, ters etkilere ait yeni sinyallerin tespiti, proaktif risk yönetimi ve başta sağlık çalışanları olmak üzere ilgili tüm taraflar arasında uygun iletişimi kurmak bulunmaktadır. Bu etkinlikler aracılığıyla ilaçların fayda / risk oranı sürekli izlenir. Hastaların yaşam kalitesinin ve hasta güvenliliğinin iyileştirilmesi ve ardından halk sağlığına katkıda bulunulması farmakovijilans etkinliklerinin nihai hedefini oluşturur. Dolayısıyla, çok paydaşlı farmakovijilans etkinlikleri önemli toplumsal, etik ve ticari etkilere sahip uluslararası bir sistem içerisinde gerçekleştirilir.

İlaçların güvenliliği ile ilgili olarak temel veriler başlıca pazarlama sonrası gözetim (sürveyans) çalıșmalarıyla elde edilir. Bu süreç ilaç piyasada kaldığı sürece devam eder. Farmakovijilans etkinlikleri çerçevesinde ilacın ters etkileriyle ilgili yeni sinyaller ilaç firmalarına bazı yükümlülükler de getirir. Bunlar hasta kullanım talimatı veya prospektüste değişim (kullanım sınırlaması) veya ilacın piyasadan çekilmesi şeklinde olabilir. İlaç idari otoritesi tarafından alınan bu kararlarda kullanılan ilaç ile ortaya çıkan ters etki arasındaki neden-sonuç iliş̧isinin kurulması oldukça önemlidir. ${ }^{2}$ Hasta ve toplum sağlığı açısından önemli bir işlevi yerine getiren farmakovijilans etkinliklerinin gelişimini, günümüzdeki faaliyet alanını, işlevini ve önemini daha iyi anlamak için bu disiplinin tarihsel evrimine daha yakından bakmak gerekmektedir. $\mathrm{Bu}$ çalışmada, farmakovijilans etkinliklerinin tarihsel evrimi farmakovijilansın kilometre taşlarından birisi olan talidomit faciası üzerinden incelenmiştir.

\section{Yöntem}

Bu derlemede 'PubMed' veri tabanı kullanılarak konumuz ile ilgili anahtar kelimeler olan "thalidomide", "pharmacovigilance", "drug safety", "lessons learnt" ile "and", "or" bağlaçları kullanılarak tarama yapılmıştır. Temel ve klinik bilimler çerçevesinde ulaşılan makaleler konu ile ilişkisine göre seçilmiş ve ihtiyaç duyulduğunda destekleyici literatürlere başvurulmuştur. Tarihsel bilgilere ulaşım için derlemelerden faydalanılmıştır. Araştırma 1960-2018 yıllarını kapsayan İngilizce makaleler ile sınırlanmıştır. Genel kural olarak tam metinli yayınlanan makaleler kullanılmış ve sadece özeti bulunan makaleler çalışmaya dahil edilmemiştir.

\section{Bulgular}

\section{Talidomidin Piyasaya Çıkışı}

Talidomit ( $\alpha$-N-ftalimido-glutarimit) (Şekil 1) ilk olarak 1953 yllında o zaman diliminde bir Batı Alman ilaç firması olan Grunenthal tarafından sentezlenmiş ve 1957 yılında Contergan ticari adıyla piyasaya çıkmıştır. ${ }^{3}$ Kıta Avrupası dışında talidomidin Kanada (Kevadon, Talimol), Japonya (İsomin), İngiltere ve Avustralya (Distaval) gibi birçok ülkede en az 37 ticari ad ile piyasaya sürüldüğü bildirilmektedir. ${ }^{4,5} \quad 0$ dönemin çok da sıkı olmayan ilaçla ilgili yasal düzenmeler ortamında talidomidin farelerde sedatif-hipnotik etkilerini gösteren ve verilerinin sorgulanabilir nitelikte olduğu tek bir çalışma bulunmaktaydı. Deney hayvanlarında kapsamlı toksikoloji çalışmaları olmaksızın, sadece bu çalışmaya dayanarak talidomidin insanlarda kullanılmaya başlandığı bilinmektedir. 1950'li yıllarda sık kullanılan barbitüratlara 
göre talidomidin ters etki profilinin oldukça iyi olduğu düșünülmekteydi: Așırı dozda apne nedeniyle ölüm potansiyelinin düşük olduğu ve bağımlılık potansiyeli olmadığı ileri sürülmekteydi. Bu nedenle reçetesiz satılmaya başlanan talidomit başarılı pazarlama tekniklerinin de etkisiyle Batı Almanya'da en çok tercih edilen "uyku hapı" oldu. Bu ülkedeki talidomit üretimi 1957'de 33 kg iken, yasaklandığı yıl olan 1961 yılında 11.060 kg'a ulaşmıştı. Bu rakamların ne kadar yüksek olduğu 1000 kilogram talidomidin 20 milyon teratojenik doza eşit olduğu düşünülürse daha iyi anlaşllabilir. Talidomidin tüm dünyada ne kadar yaygın kullanıldığını daha iyi anlamak için önerildiği klinik durumlara bakmak da yeterlidir: Sinirlilik, zayıf konsantrasyon, anksiyete, uykusuzluk, hipertiroidizm, hipertansiyon, migren ve hatta bulaşıcı hastalıklar gibi çeşitli endikasyonlara, Richardson-Merrill firması alkolizm, anoreksiya, astım, kanser, zayıf okul başarısı, erken boşalma, psikasteni ve tüberkülozu da ekledi. Trajik bir şekilde, klinisyenlerin gebeliğin neden olduğu "sabah bulantısı" ve kusmalarında da faydalı etkileri olduğunu kabul etmesiyle talidomit antiemetik olarak hiçbir çekince olmadan gebelerde kullanılmaya başlandı. ${ }^{6-9}$

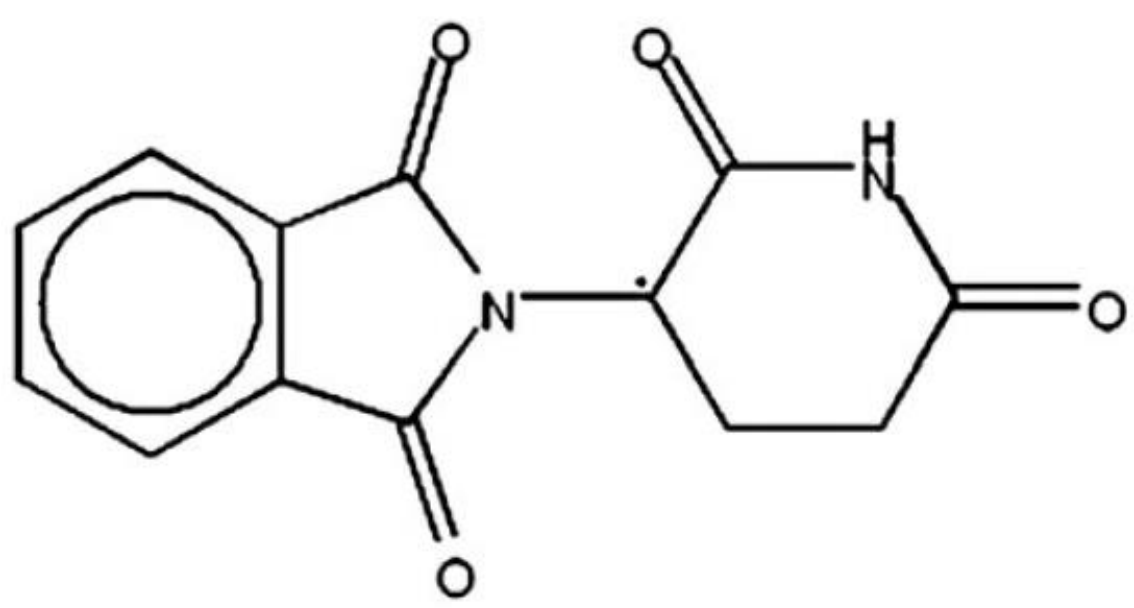

Şekil 1. Talidomidin kimyasal formülü. “.”asimetrik karbon atomuna işaret etmektedir. ${ }^{3}$

\section{Talidomidin Teratojenik Etkisinin Ortaya Konulması}

Gebelikleri sirasında talidomit kullanan annelerin fokomelili bebeklerine ait ilk vaka raporları ortaya çıkmaya başlayınca farmakovijilans tarihçesinde bir dönüm noktasına gelinmiş olundu. 1961 yılı Kasım ayında, Dr. Lenz, bir Pediatri Kongresinde gebelik sırasında talidomit kullanan annelerden doğan 52 bebeğe ilișkin verileri sundu; konjenital malformasyonlar ile talidomit arasında bir korelasyon olduğu şüphesini bir Alman gazetesinde (Welt am Sonnatag) yayınlandı. Sonrasında Almanya, Belçika, İsveç ve İngiltere'deki doktorlardan benzer șekilde etkilenmiș bebeklere ait 115 vaka bildirimi daha aldı. Dr. Lenz 1962'de Lancet'te yayınlanan mektubunda, toplanan vakalarda ekstremite bozukluğu dahil olmak üzere bulgulardaki özgüllüğe dikkati çekti. ${ }^{10}$

Avustralyalı Dr. McBride ise 1961 yılının Aralık ayında, saygın bir tıp dergisi olan Lancet Journal'ın editörüne, bebeklerin konjenital malformasyonu ile talidomit arasında bir bağlantı olabileceğine dair bir mektup yazdı. Bu mektupta, gebelikte taban (base-line) konjenital malformasyon insidansının (\%1.5-2), talidomit kullanan gebelerde \%20'ye kadar artış gösterdiğini bildirdi ve diğer doktorlara gebelik sırasında bu ilaçları alan annelerin bebeklerinde de bu anormalliklerin olup olmadığını sordu. ${ }^{11}$

$\mathrm{Bu}$ derece yaygın kullanımının bir sonucu olarak, Batı Almanya'da 5.000 bebek deformiteyle doğdu. En fazla ikinci talidomit satışı İngiltere'de gerçekleștiği için 349 vaka 
ile ikinci en fazla insidans bu ülkede görüldü. Talidomit üreticilerine karşı birçok dava açıldı. Batı Almanya'da Grunenthal firması ve dokuz çalışanına karşı cinayet ve ihmal suçlamalarıyla açlan davada firma hayatta kalan 2.000 çocuğun ebeveylerine 1969 yılında 30.000 .000 dolarlık bir tazminat ödemek zorunda kaldı. ${ }^{12}$

ABD'de, talidomit trajedisi gözlenmedi, çünkü Gıda ve İlaç Dairesi (Food and Drug Administration; FDA) çalışanı Dr. Frances Kelsey gebelikte talidomit kullanımının güvenliliği hakkında güçlü şüphelere sahipti ve talidomidin Amerikalı ruhsat sahibinin (William S. Merrell Company) kapsamlı güvenlilik testleri olmadan ilacını piyasaya çıkarmasını engelledi. 7,13 Dr. Kelsey'in bu çabasına rağmen, talidomit, ABD'de yapılan ilaç çalışmalarının bir parçası olarak 1.267 hekim tarafından, 3.760'ı çocuk doğurma yașında kadınlar olmak üzere 19.822 hastaya dağıtıldı. ABD'de yalnızca 17 talidomit vakasına rastlandı. Bu vakaların 7'sinde talidomidin yabancı kaynaklardan temin edildiği bildirilmektedir. ${ }^{14}$

Gebelikleri sırasında tek bir talidomit dozu alanlarda bile teratojenik etkinin görüldüğü ve konsepsiyondan sonraki 3 . ve 8. haftalar arasinda teratojenisite riskinin en yüksek olduğu bilinmektedir.,4,8 Talidomidin neden olduğu konjenital bozukluklar talidomit embriyopatisi olarak adlandırıldı. Talidomit embriyopatisinin en göze çarpan özelliği fokomelidir. Fokomeli hem üst hem de alt ekstremitelerin yokluğu veya malformasyonu olarak bilinmektedir. Bu terim, Yunanca phoco (fok balığı) ve melos (uzuv) kelimelerinden türetilmiştir ve talidomit bebeklerinin malforme ekstremitelerinin fok balığının yüzgeçlerine benzerliğine işaret etmektedir (Fotoğraf 1). Fokomeliye ek olarak yüz, göz, kulak, dış jenital organlar, omurga, kalp, böbrek ve bağırsak gibi birçok organda görülen ciddi fenotip bozuklukları da bulunmaktadır. ${ }^{15,16}$

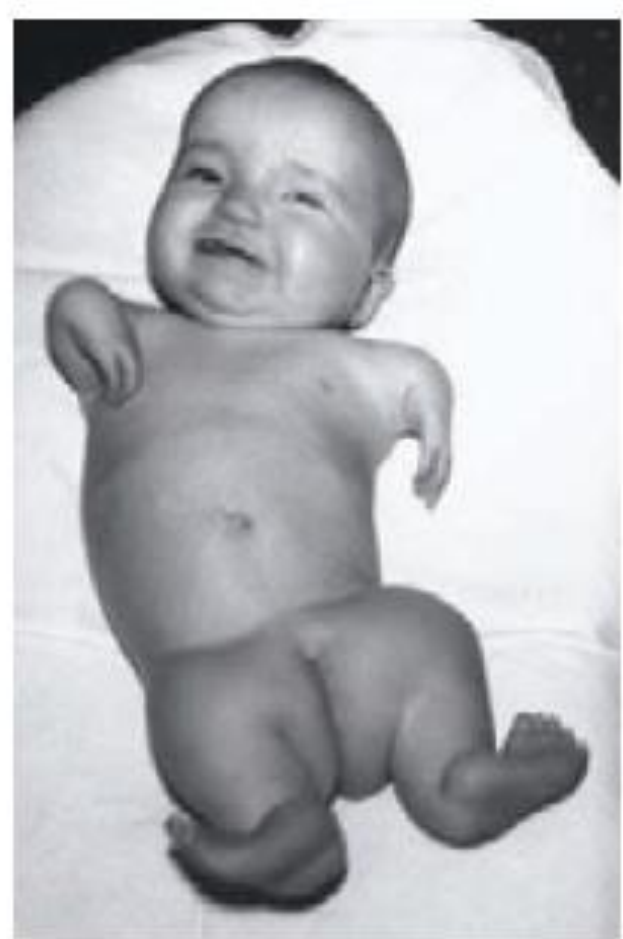

Fotoğraf 1. Fokomelili bir bebek ${ }^{23}$

Talidomit piyasadan çekilinceye kadar kaç gebenin kullandığ bilinmemektedir. Deformiteli bebek sayısının tüm dünyada toplam 7.000-10.000 arasında olduğu kestirimi yapılmaktadır. Talidomidin neden olduğu potansiyel düşük ve ölü doğumlar da göz önüne alınırsa etkilenen toplam bebek sayısının çok daha fazla olduğu düșünülmektedir.14,17,9

\section{Talidomidin İlaç Piyasasına Geri Dönüşü}

1964 'te İsrailli bir doktor olan Jacob Sheskin, talidomidi ağrıyla birlikte uykusuzluk şikayeti olan ileri derecede eritema nodozum leprosum (ENL; inflamatuvar özellikte kütanöz lepranın bir formu) hastasında denedi. Elde ettiği sonuçlar dramatikti: Hasta, ertesi gün hiçbir artık (hangover) etki görülmeyecek şekilde uyudu ve ENL ile ilgili ağrı ve ateși tamamen düzeldi ve üç gün içerisinde kütanöz yaraları iyileşti. Hasta talidomit kullandığı sürece ENL semptomlarından şikayetçi olmadı. ${ }^{18} \mathrm{Bu}$ terapötik etki diğer ENL hastalarında da doğrulandı. 19

1994 yılında ise D'Amato ve ark. talidomit ile ilişkili malformasyonların ilacın 
vaskülojenezi bozucu etkisinin bir sonucu olduğunu ve benzer bir mekanizmanın solid tümörlerde görülen kan damarlarının gelişimini önleyebileceğini ileri sürdü. Talidomidin anjiyojenezi inhibe edici etkisi tavşan kornea mikro-cep eseyinde (corneal micropocket assay) doğrulanmıştır.20,21 Günümüzde talidomidin antianjiyojenik etkisinin, fokomeli dahil olmak üzere talidomit embriyopatisi fenotiplerinin çoğundan sorumlu olduğu düşünülmektedir. ${ }^{17}$

Talidomidin antiinflamatuar, immün sistemi modüle edici ve anti-anjiyojenik özelliklerinin ortaya çıkarılması ilacın diğer klinik durumlarda da kullanımına ilgiyi artırdı. $^{20} 1998$ yılında, talidomit FDA tarafından ENL tedavisi için ve daha sonra 2006 yllında, multipl miyeloma tedavisi için onay aldı. Ancak gebelerin ilaca maruziyetini önlemek için sıkı kısıtlamalar altında kullanılması gerekiyordu. 22,23

Sonuç olarak ilaçla tedavide insan eliyle yaratılmış en büyük facia olarak değerlendirilen talidomit yaklaşık 60 yll sonra yukarıda sayılan hastalıklarda kullanılmak üzere ruhsat alarak ilaç piyasasına geri döndü. Böylece ilaç güvenliliğine yeni bir bakış açısının getirilmesiyle farmakovijilans etkinliklerinde yeni bir aşamaya geçilmiş oldu.

\section{Talidomit Faciası ve Farmakovijilans Etkinliklerinin Gelişimi}

\section{a. İlaç Güvenliliğine Ait Yasal Düzenlemeler}

Talidomit faciasının deney hayvanlarında yapılan preklinik çalışmaların önemini, kestirim gücünü ve eksikliklerini net bir şekilde ortaya koymasıyla birlikte ABD'de, Gıda, İlaç ve Kozmetik yasasında (1962) ilaca ait güvenlilik verilerinin artırılması yoluna gidildi. $\mathrm{Bu}$ şekilde, insanlarda kullanıma geçilmeden önce üreme toksikolojisi çalışmalarının sadece kemirgenlerde değil tavşan veya maymun gibi kemirgen olmayan farklı hayvan türlerinde yapılması zorunluluğu getirildi. Çünkü kemirgenler talidomidin teratojenik etkilerine sinırlı duyarlılık göstermektedir.6,24 Diğer taraftan, Gıda, İlaç ve Kozmetik yasasına ilaç piyasaya çıkmadan önce etkinlik verilerinin eklenmesi zorunlu hale getirildi. Benzer şekilde, Avrupa'da (1965), 65/65 sayılı AB Direktifi ile Avrupa ilaç mevzuatının gelişimi sağlandı. 1968'de DSÖ Uluslararası İlaç İzleme Programı kurulmasiyla farmakovijilans etkinlikleri uluslararası bir niteliğe büründü.

\section{b. Spontan Bildirim Sistemlerinin Doğuşu}

Ters etkilerin ortaya çıkarılması için günümüzün modern ve oldukça karmaşık şekilde yapılandırılmış elektronik kayıtlarının kullanımının başlangıcını klinisyenler tarafından önemli ve saygın bilimsel dergilere gönderilen mektuplar veya uyarılar oluşturmuştur. Bu mektuplar bir anlamda ilk vaka raporlarını/serilerini olușturmaktadır. Talidomit faciası farmakovijilans etkinlikleri içerisinde ters ilaç reaksiyonlarının spontan bildirimlerinin sistematik, organize ve yasal düzenlemeye tabi hale getirilmesini sağladı. 1964'te, İngiltere'de ters ilaç etkilerine ait spontan bildirimde kullanılan özel bir form olan "Sarı Kart" (Yellow Card) sistemi oluşturuldu. ${ }^{25}$

\section{c. Risk Yönetimi}

Talidomidin pazara çıkış sonrası dikkatli bir şekilde izlemi ve yeni kontrol yasalarının bir araya gelmesiyle bugün, talidomid, zararları kadar faydalarıyla da anılmaktadır. Talidomidin kullanımı, örneğin ABD'de "THALOMID Risk Değerlendirme ve Azaltma Stratejisi" gibi sıkı kurallar altında dikkatle izlenmektedir. Benzer șekilde akneye karșı kullanılan izotretinoin doğum defektleri ile ilgili endișelerden dolayı dikkatli bir gözlem altına alınmıștır. Günümüzde teratojenik özellikleri bilinen bu tür ilaçlar alınan önlemler sayesinde toplumda güvenle kullanılabilmektedir. ${ }^{23}$

\section{d. Gebelikte akılcı ilaç kullanımı}

İnsan fetüsünün kutsalların kutsalı "sanctum sanctorum" uterusta ilaç maruziyetinden korunduğuna dair inanç talidomit bebeklerinin doğumuyla paramparça oldu. ${ }^{26}$ Talidomit faciası ile 
birlikte gebelikte ilaç kullanımı farmakovijilans etkinlikleri içerisinde önemli yer tutan bir alan haline gelmeye başladı: Bir ilacın ters etkilerine karşı tetikte olmanın belki de en çok gerektiği alan olarak teratoloji ve toplumun en hassas grubu olarak da gebeler ön plana çıkmaya başladı. Etik nedenlerle (klinik denemelere gebe ve emziren kadınların dahil edilmemesi sonucu) informasyonun fazla olmadığı bu özel popülasyon altgrubunda, klinikte karar verilmesi oldukça zordur. Ders kitabı bilgilerinin yeterli olmadığı, FDA kategorisinin geçerliliğini yitirmeye başladığ $1^{27}$ bu noktada kanıta dayalı tedavi ilkelerinin yanısıra sağduyulu ve iyi bir iletişim kurucu özellikler de ön plana çıkmaya başlamıştır. Sağlık çalışanları için bu durum gebelikte ilaç kullanımı veya reçetelenmesini sürekli vijilans gerektiren bir alan olarak karşımıza çıkarmaktadır.

\section{Tartışma ve Sonuç: Yeterince Ders Alındı mi?}

Geçmişteki vakaların gözden geçirilmesi oldukça önemli ve öğretici olsa da, talidomit reçetelerinin sıkı bir şekilde kontrol edilemediği ve lepranın endemik oranlarda görüldüğü gelişmekte olan Brezilya, Arjantin gibi Güney Amerika ülkelerinde talidomit embriyopatili bebeklerin hala doğduğu bildirilmektedir. ${ }^{5}$

Gebelerde talidomit kullanımı modern ilaçla tedavi tarihçesinde insan eliyle yaratılmış en büyük facia olarak kabul edilmektedir. Öncesinde her ne kadar çeşitli ilaç faciaları (örn., dietilen glikol) yaşansa da talidomit bebekleri halkta derin bir infial yaratmıştır. Talidomit faciası sadece bebeklerin yaşamlarını yitirmeleri veya dramatik bir teratojenik etkiye maruz kalmalarının ötesindedir: Geniş halk kitleleri, ilaç firmalarının aç gözlülüğü ve teknolojiye aşırı güvenin ne kadar tehlikeli boyutlara ulaşabileceğini ilk kez bu kadar net anlamaya başlamıştır. $\mathrm{Bu}$ bağlamda talidomit faciası teknolojinin yenilmezliğine ve mutlak güven duyulmasına koşulsuz inancın bir sembolü olan Titanik faciası ile karşılaştırılmıştır. ${ }^{28} \mathrm{Bu}$ sancılı geçiş dönemi "modern sentetik ilaçlar"dan daha çok Tamamlayıcı ve Alternatif Tedavi kapsamındaki diyet suplemanları, bitkisel veya homeopatik ürünler gibi "doğal veya folklorik tedavi”yi ön plana çıkartmaya başlamıştır. Ancak bu ürünlerin tıpkı talidomit gibi güvenlilik ve etkinlik verileri eksiktir ve halk sağlığını tehdit edici durumlar oluşturabilmektedir. ${ }^{29}$ Sonuç olarak, kalitesi, güvenliliği ve etkinliği kontrol altında olmayan her türlü tedavi edici ürün, geçmişten ders alınmadığı sürece, talidomit gibi günümüzde de önemli halk sağlığı tehditleri oluşturmaya devam etmektedir. $\mathrm{Bu}$ koşullar altında farmakovijilans etkinliklerinin önündeki en büyük engellerden birisinin de geçmişten ders almamak olduğunu söyleyebiliriz.

\section{Yazarların yazıya katkıları}

Cüneyt Kemal Buharalığlu: Derleme konusunun bulunması, yayınların toplanması, giriş, yöntem, bulgular, tartışma ve sonuç bölümlerinin oluşturularak derlemenin yazılması

Gökçe Yıldırım Buharalığlu: Yayınların toplanması, giriş, yöntem, bulgular, tartışma ve sonuç bölümlerinin oluşturularak derlemenin yazılmasına katkı.

\section{Kaynaklar}

1. World Health Organization. The Importance of Pharmacovigilance. Erişim yeri:

http://apps.who.int/medicinedocs/en/d /Js4893e/, Erişim tarihi: 2.10.2018.

2. Pharmacovigilance Risk Assessment Committee: PRAC strategy on measuring the impact of Pharmacovigilance activities. Erişim yeri: http://www.ema.europ a.eu/docs/en_GB/docum ent_libra ry/Other/2016/01/WC500 19975 6.pdf, Erişim tarihi: 2.10.2018.

3. James HK, Anthony RS. Thalidomide: The Tragedy of Birth Defects and the Effective Treatment of Disease. Tox Sci 2011;122(1); 1-6.

4. Mellin GW, Katzenstein M. The saga of thalidomide: neuropathy to embryopathy, with case reports of congenital anomalies. $N$ Engl J Med 1962; 267: 1184-92. 
5. Vargesson N. The teratogenic effects of thalidomide on limbs. J Hand Surg Eur 2018 Vol. 2018; 1753193418805249.

6. Schumacher HA. Comparison of the teratogenic activity of thalidomide in rabbits and rats. J Pharmacol Exp Ther 1968; 160; 189-199.

7. McFadyen R. Thalidomide in America: A brush with tragedy. Clio Medica 1976; 11: 79-93.

8. Lenz W. A short history of thalidomide embryopathy. Teratology 1988; 38: 20315.

9. Smithells RW, Newman CHG. Recognition of thalidomide defects. J Med Genet 1992; 29:716-723.

10. Lenz W, Knapp K. Foetal malformations due to Thalidomide. German Med 1962;7:253-8.

11. McBride WG. Thalidomide and congenital abnormalities. Lancet. 1961; ii:1358.

12. Curran, W. The thalidomide tragedy in Germany: The end of a historic medicolegal trial. New Engl J Med, 1971; 284: 481-482.

13. Kelsey, F. Thalidomide update: regulatory aspects. Teratology 1988; 38: 221-226.

14. Lenz, W. Malformations caused by drugs in pregnancy. Am J Dis Child, 1966; 112: 99-106.

15. Lenz W. 1962. Thalidomide and congenital abnormalities [letter]. Lancet 279:303-305.

16. Newman CGH. The thalidomide syndrome: risks of exposure and spectrum of malformations. Clin Perinatol 1986; 13:555-573.

17. Vargesson N. Thalidomide-induced teratogenesis: History and mechanisms. Birth Defects Res C Embryo Today 2015; 105: 140 - 156 .

18. Sheskin J. Thalidomide in the treatment of lepra reactions. Clin Pharmacol Ther 1965; 6: 303-306.

19. Sheskin J, Convit J. Results of a double blind study of the influence of thalidomide on the lepra reaction. Int J Lepr Other Mycobact Dis 1969; 37: 135146.

20. D'Amato RJ, Loughnan MS, Flynn E, Folkman J. Thalidomide is an inhibitor of angiogenesis. Proc Natl Acad Sci USA 1994; 91: 4082-4085.
21. Kenyon BM, Browne F, D'Amato RJ. Effects of thalidomide and related metabolites in a mouse corneal model of neovascularization. Exp Eye Res 1997; 64: 971-78.

22. Uhl K, Cox E, Rogan R, Zeldis JB, Hixon D. Thalidomide use in the US: experience with pregnancy testing in the S.T.E.P.S. programme. Drug Saf 2006;29:321-329.

23. Patient Guide to (THALOMID REMS ${ }^{\text {TM}}$ ) Risk Evaluation and Mitigation Strategy (REMS) $^{\mathrm{TM}} \quad$ Program. Erişim yeri: https://www.fda.gov/downloads/forind ustry/userfees/

prescriptiondruguserfee/ucm361111.ht m, Erișim tarihi: 23.10.2018

24. Wells PG. A new target for thalidomide. Nat Chem Biol 2018;14(10):904-905.

25. YellowCard. Erișim yeri:https://yellowcard.mhra.gov.uk/mo nitoring safety/.Erişim tarihi: 20.10.2018.

26. Dally A. Thalidomide: was the tragedy preventable? Lancet 1998;351: 11971199.

27. Buharalioglu CK, Acar S, Erol-Coskun H, Küçüksolak G, Karadas B, Kaya-Temiz T, Kaplan YC. Pregnancy outcomes after maternal betahistine exposure: A case series. Reprod Toxicol 2018;79:79-83.

28. George J. Annas, JD, Sherman E. Thalidomide and the Titanic: Reconstructing the Technology Tragedies of the Twentieth Century. Am J Public Health 1999;89(1): 98-101.

29. Ahmed M, Hwang JH, Choi S, Han D. Safety classification of herbal medicines used among pregnant women in Asian countries: a systematic review. BMC Complement Altern Med. 2017;17(1):489. 